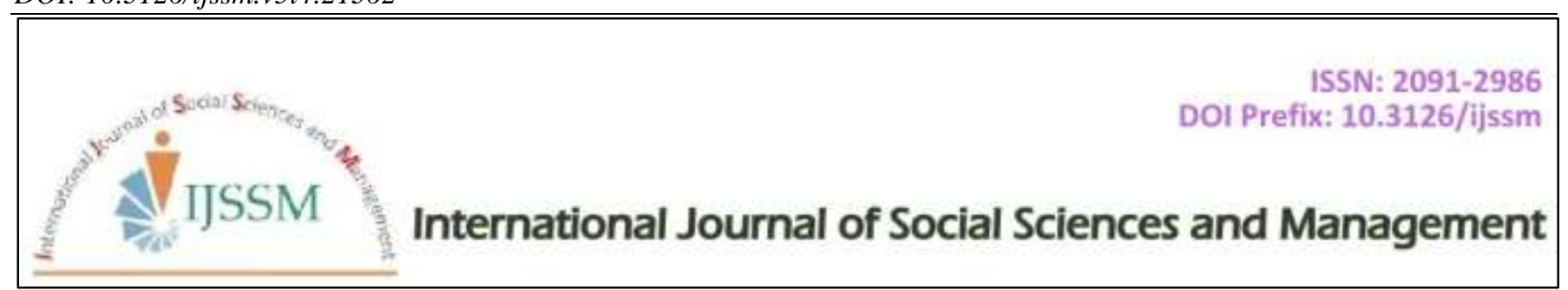

Editorial

\title{
An Incredible Five Years of Journal
}

We should not give up and we should not allow the problem to defeat us.

-A. P. J. Abdul Kalam

It is an account of five years' performance report of "International Journal of Social Sciences and Management" showing ups and downs in this tenure. Data shows that 391 manuscripts received till the date of writing this editorial which was reviewed and evaluated for publication in five volumes, each volume having four issues. It the average of around 9 papers per issue and 36 papers per volume. It can be seen on the journal's website that 22 papers published in $1^{\text {st }}$ volume, 49 in $2^{\text {nd }}$ volume, 43 in $3^{\text {rd }}$ volume, 36 in $4^{\text {th }}$ volume, and 31 papers in $5^{\text {th }}$ volume, altogether 181 papers in 5 years shows that rate of acceptance is only $46 \%$. We are fully satisfied with the performance of the journal. Our satisfaction is fully based on the quality and original publication. We are extremely sorry for excluding 210 manuscripts during these five years on the ground of plagiarism, lack of originality and poor quality of English. We really appreciate efforts of those authors who revised manuscripts according to the suggestions given by our potential reviewers and made our journal successful. Publication is only successful by the readers and citations of the papers of new work publication in various journals and academic literatures. The review of our readers by collecting download data from own website, NepJOL and various accessible indexing databases, we find that readers number have been increased exponentially. Morning shows the day is well known proverb, it is evident with the data that maximum publication in $2^{\text {nd }}$ year and a little decrease in $3^{\text {rd }}$ to $5^{\text {th }}$ year due increasing review process towards maturity. In the first year only 25 reviewers joined our team which is increased up to 119 in the tenure of five years. The joining of qualified potential reviewers with in the increasing credibility of this journal has reduced the percentage of acceptance and increased the percentage of major corrections and rejection is not our failure but we are feeling proud to maintain our standard of publication. I would like to thanks all authors who submitted their manuscripts, without their submission the journal may not success. The help of reviewers and our editorial team should be fully acknowledged here in the presentation of five years' performance report as the editorial of $4^{\text {th }}$ issue of $5^{\text {th }}$ volume. It is concluded with following quotation.

Adopting the right attitude can convert a negative stress into a positive one.

-Hans Selye

Umesh Prasad Shrivastava

Editor-in-Chief

International Journal of Social Sciences and Management 